REVISTA DE DERECHO UNED, NÚM. 27, 2021

\title{
LA SECUELA COMO OBRA DERIVADA
}

\author{
THE SEQUEL AS A DERIVATIVE WORK
}

FERNANDO RAVELO GUILLÉN

Doctorando en el Programa de Doctorado en Unión Europea (UNED)

Sumario: I. El punto de partida: la obra original y su originalidad. II. El ius transformandi y las formas de la obra. 1. La forma interna y externa. 2. Los criterios para comprobar la conexión entre distintas obras. 3. La autorización como requisito fundamental de la transformación. A. Naturaleza de la autorización. B. Sujetos legitimados y formalidades para prestar la autorización. III. La secuela como resultado de la transformación llevada a cabo sobre los aspectos estructurales de la obra. 1. Orígenes de la secuela. 2. Consideraciones terminológicas. 3. Concepto. IV. Figuras similares. 1. El remake. 2. El spin off. V. Conclusiones.

Resumen: La secuela se trata de una obra que, de la misma forma que ocurre con otras obras derivadas, no tiene una regulación específica en nuestra legislación de propiedad intelectual. Esto ocurre a pesar de que no es una figura de creación reciente. La secuela se ha manifestado en diferentes medios, dependiendo del momento histórico. En un principio, su aparición se produjo en la literatura y más tarde en el medio audiovisual y cinematográfico. Existen determinados criterios que servirán para distinguirla de la obra originaria de la que ha surgido, así como de otras obras derivadas, en función de su grado de originalidad.

Palabras clave: Secuela, Obra derivada, Originalidad, Derechos de Autor, Propiedad Intelectual. 
Abstract: The sequel is a work that, in the same way as other derivative works, does not have a specific regulation in our intellectual property legislation. This occurs despite the fact that it is not a recently created figure. The sequel has been manifested in different media, depending on the historical moment. At first, its appearance occurred in literature and later in the audiovisual and cinematographic medium. There are certain criteria that will serve to distinguish it from the original work from which it has emerged, as well as from other derivative works, depending on its degree of originality.

Key words: Sequel, Derivative Work, Originality, Copyright, Intellectual Property.

Recepción original: 27-7-2020

Aceptación original: 14-10-2020

\section{EL PUNTO DE PARTIDA: LA OBRA ORIGINAL Y SU ORIGINALIDAD}

En nuestro ordenamiento jurídico, es del art. 10 del Real Decreto Legislativo 1/1996, de 12 de abril, por el que se aprueba el Texto Refundido de la Ley de Propiedad Intelectual, regularizando, aclarando y armonizando las disposiciones legales vigentes sobre la materia (en adelante TRLPI), del que se deduce que la creación, como objeto de propiedad intelectual, precisa la exteriorización o plasmación en una forma que debe ser, sin lugar a dudas, perceptible ${ }^{1}$.

Lo que realmente constituye el objeto de protección de la propiedad intelectual es la obra, como producto o resultado concreto del proceso creativo, y no las ideas ${ }^{2}$ o los conocimientos expresados a través de la obra. En el mismo sentido se ha pronunciado el Tribunal Supremo al decir que "la idea, como mera elucubración del pensamiento, no es un objeto apropiable por ser indefinida en sus perfiles y, por tanto, no cognoscible, lo que impide su apropiación y reproducción”3.

Vid. por todas SAP Madrid, de 17 de septiembre de 2015 (ROJ: 13009/2015).

2 SOL MUNTAÑOLA, M.A. «La protección de las ideas». Tecnos. Madrid. 1997, págs. 9 y ss., recoge la opinión mayoritaria al afirmar que "para extender el manto de su protección, nuestro ordenamiento jurídico exige el requisito de la exteriorización y plasmación en una realidad concreta, razón por la cual la idea como tal no es protegible a través de ninguno de los sistemas legales especialmente establecidos".

3 STS de 24 de junio de 2004 (ROJ: 4443/2004). 
La exclusión de las ideas como objeto de protección del derecho de autor se trata de una cuestión ampliamente aceptada. Tal y como ha señalado la Sentencia de la Audiencia Provincial de Madrid de 2 de julio de 20094: "ha de partirse del principio general, establecido en tratados internacionales suscritos por España ${ }^{5}$, aceptado por la generalidad de la doctrina, declarado por la jurisprudencia del Tribunal Supremo ${ }^{6}$ y compartido por otros ordenamientos jurídicos de nuestro entorno, de que las ideas no son en principio objeto de protección por la propiedad intelectual".

La citada sentencia prosigue señalando que lo que es susceptible de propiedad intelectual y, consecuentemente, de protección por parte del derecho de autor es la obra literaria, artística o científica, pero no las ideas, ya que éstas incluso si gozaran de un alto grado de originalidad nunca podrán ser apropiadas, al ser un patrimonio común de la humanidad 7 .

No obstante, cabría puntualizar que a pesar de que las ideas, como abstracción, no formen parte del derecho de autor, no existiría problema alguno para que a la hora de crear una obra se pudiese recurrir a aquéllas como una fuente de inspiración legítima.

Por otro lado, conforme se desprende del citado art. 10 TRLPI, entraría en juego el requisito de la originalidad, si bien hay señalar que nuestro legislador, al igual que sucede en otros ordenamientos jurídicos, no proporciona una definición.

4 SAP Madrid de 2 de julio de 2009 (ROJ: 10728/2009).

5 Uno de los tratados internacionales suscritos por España, en los que se recoge este principio general es el "Acuerdo sobre los Aspectos de los Derechos de Propiedad Intelectual relacionados con el comercio" (al que se suele hacer referencia por sus siglas "ADPIC" o en inglés "TRIPS"), ratificado por España por Instrumento de 30 de diciembre de 1994. En su art. 9-2 establece que "la protección del derecho de autor abarcará las expresiones, pero no las ideas, procedimientos, métodos de operación o conceptos matemáticos en sí".

6 Así se recoge en las sentencias de la Sala $1^{\text {a }}$ del Tribunal Supremo de 20 de febrero y 26 de octubre de 1992 y las núm. 563/1995, de 7 junio y núm. 1125/2003, de 26 noviembre, entre otras, que siguen la línea jurisprudencial iniciada por las antiguas sentencias de 25 de abril y 12 de agosto de 1900 y 18 de noviembre de 1903 .

7 Respecto a este último extremo, el tribunal ofrece el siguiente ejemplo: "lo que es objeto de la propiedad intelectual es la obra 'La interpretación de los sueños' de Sigmund Freud (del que están a punto de cumplirse 70 años de su muerte), pero no las ideas que integran el llamado psicoanálisis freudiano, que inspiran la referida obra y se plasman en la misma, que pertenecen al dominio público por más que su creador fuera Sigmund Freud y tales ideas estuvieran dotadas de una gran originalidad y revolucionaran en su día el campo de la psicología y de la psiquiatría”. 
Según MARCO MOLINA la originalidad se trata de un término que no es jurídico, además de ser ambiguo ${ }^{8}$. Y en términos similares se ha pronunciado la jurisprudencia", al decir que la "«creación original», en la dicción legal, es un concepto jurídico indeterminado"

La originalidad, como apunta BERCOVITZ RODRIGUEZ-CANO podría entenderse en base a dos criterios: uno objetivo y otro subjetivo $^{10}$, siendo este autor partidario del primero. Sin embargo, el TRLPI tampoco contiene referencia alguna acerca del carácter objetivo o subjetivo de la originalidad, con la única excepción de los programas de ordenador ${ }^{11}$.

La jurisprudencia española es partidaria del criterio objetivo, que se encuentra ligado en términos generales a la idea de singularidad, que sería apreciada en aquellas ocasiones en las que el autor de una obra incorporase una especificidad que posibilitara que la impresión que produce en el destinatario le permitiese distinguirla de otras similares o parecidas, además de reunir una cierta apariencia de peculiaridad ${ }^{12}$.

En cambio, en otros países el criterio a seguir sería el subjetivo, como es el caso de Francia o Estados Unidos ${ }^{13}$. La originalidad se consideraría como un reflejo de la personalidad del autor de la obra. Desde esta perspectiva, sin embargo, se podrían producir situaciones peculiares, tales como que un autor crease una obra igual a una

8 MARCO MOLINA, J., "La formación del concepto de derecho de autor y la originalidad de su objeto", en Macías Castillo, A., y Hernández Robledo, M.A., (coord.), El derecho de autor y las nuevas tecnologías. Reflexiones sobre la reciente reforma de la Ley de Propiedad Intelectual, La Ley, julio 2008, pág. 304.

9 STS (Civil) de 5 abril de 2011 (EDJ: 2011/60597)

10 BERCOVITZ RODRIGUEZ-CANO, R., “Comentario al art. 10", en Comentarios a la Ley de Propiedad Intelectual (coord. R. Bercovitz Rodriguez-Cano), $4^{\mathrm{a}}$ ed., Tecnos, Madrid, 2017. pág. 162.

11 El art. 96.2 TRLPI señala que "el programa de ordenador será protegido únicamente si fuese original, en el sentido de ser una creación intelectual propia de su autor". La redacción de este artículo es fruto de la trasposición en nuestro ordenamiento jurídico del art. 1.3 de la Directiva 91/250/CEE.

12 Como señala la SAP Madrid, de 17 de septiembre de 2015 (ROJ: 13009/2015), el Tribunal Supremo emplea este criterio en las sentencias de 24 de junio de 2004 y 5 de abril de 2011 (en la que se señala que cabe entender la noción de "creación original» del artículo 10.1 LPI como «originalidad creativa»), resultando igualmente identificable en las de 18 de diciembre de 2012 («aportación creativa que reúna suficiente originalidad») y en la de 25 de junio de 2013 («originalidad y altura creativa necesarias para ser considerada como "obra» protegida por la propiedad intelectual»).

13 BERCOVITZ RODRIGUEZ-CANO, R., "Comentario al art. 10", en Comentarios a la Ley de Propiedad Intelectual (coord. R. Bercovitz Rodriguez-Cano), $4^{\mathrm{a}}$ ed., Tecnos, Madrid, 2017. pág. 162. 
ya existente, creada por otro autor, sin que hubiese existido copia. Esto se conoce como "encuentros fortuitos", que siguiendo a SÁNCHEZ ARISTI, ocurrirían "cuando las semejanzas entre dos obras no provienen de la deliberada imitación de una de ellas por parte del autor de la otra, sino de una coincidencia puramente casual aunque usualmente achacable a la existencia de fuentes comunes de inspiración, o a los imperativos de una moda o fórmula compositiva"14. No obstante, para este autor tales situaciones solo parecen posibles si la obra de mayor antigüedad nunca hubiera sido publicada.

Merece destacar, no obstante, que la tendencia en los tribunales europeos se inclina hacia la adopción del criterio subjetivo. En efecto, en las Conclusiones del Abogado General del Tribunal de Justicia de la Unión Europea (en adelante TJUE), presentadas el 6 de febrero de 2020, (en relación con el Asunto C-833/18. SI, Brompton Bicycle Ltd. contra Chedech/Get2Get) ${ }^{15}$, el Abogado destaca que la propia jurisprudencia del TJUE considera que el elemento de la originalidad de una obra debe reflejar la personalidad del creador de la misma. Además, cita la Sentencia del caso Cofemel en el cual no se permitió vincular la originalidad de la supuesta obra (en el caso concreto, prendas de vestir) con sus componentes estéticos.

\section{EL IUS TRANSFORMANDI Y LAS FORMAS DE LA OBRA}

La originalidad de la obra derivada o en transformación no es algo que atañe solo a la obra original. La obra derivada o en transformación es un producto, una obra que tempranamente se vio acogida en la protección del derecho de autor. Recordemos que comenzando por las traducciones se entendió que la obra derivada tenía su propia individualidad medida ésta en función de su originalidad, aunque se basase en una obra anteriormente protegida. Por ello, la redacción del art. 11 TRLPI, con su enumeración detallada de obras prototipo de obras derivadas incluye una puerta abierta también a la posibilidad de enjuiciar el tipo o grado de originalidad que individualice la obra derivada. Es consciente el legislador, como lo es cuando otorga la protección a la obra originaria, que la originalidad, o mejor, el enjuiciamiento de la suficiente originalidad es inabarcable, por lo que prefiere no entrar en determinar criterios de análisis que podrían obstaculizar la conceptualización de una obra como en

14 SÁNCHEZ ARISTI, R., La propiedad intelectual sobre las obras musicales, $2^{\mathrm{a}}$ Ed., Comares, Granada, 2005, pág. 328.

15 Vid. https://eur-lex.europa.eu/legal-content/ES/TXT/?qid=1590348917076\&uri =CELEX:62018CC0833. (Última consulta 24 de mayo de 2020).

(C) UNED. Revista de Derecho UNED, núm. 27, 2021 
transformación. Sabe que la doctrina jurisprudencial se encargará de detallarlos en función de los casos, tipos de obras, y sus elementos o componentes.

El enjuiciamiento de dicha originalidad supone el enjuiciamiento del derecho de transformación de la obra que se discute tanto si no hay autorización del autor de la obra originaria como si se sobrepasan los límites y que pasamos inmediatamente a analizar.

\section{1. La forma interna y externa}

A la hora de determinar qué es lo que ha sido objeto de protección por parte del derecho de autor, se suele distinguir por un lado entre los aspectos formales o la estética de una obra y por otro, su contenido, entendido como la materialización de las ideas del autor.

La relevancia de contemplar una obra desde esos dos aspectos formales, tiene especial trascendencia cuando se produce la transformación de una obra, como en el caso de la secuela. Siguiendo a AYLLÓN SANTIAGO se podría definir la transformación de la obra como aquella modificación que, realizada sobre la obra originaria, ya incida sobre el contenido, ya sobre la forma de expresión de la misma, posibilite que se pueda identificar la misma en la obra que resulte, la cual habrá de reunir la suficiente originalidad para ser calificada como obra conforme a la propiedad intelectual ${ }^{16}$.

La anterior definición pone de relieve dos aspectos relevantes que se tendrán que considerar cuando se hable de la transformación de una obra, a saber, el contenido y la forma externa.

Esta distinción entre contenido y forma externa no es reciente, como no lo es que se siga hoy en día poniendo de manifiesto en recientes casos en proceso de enjuiciamiento por el TJUE, como se ha apuntado más arriba.

Pero la distinción entre contenido y forma se atribuye a la doctrina alemana de finales del siglo XIX, y fue adoptada por la doctrina de distintos países europeos tales como Francia ${ }^{17}$ o España,

16 AYLlÓN SANTIAGO, H., El derecho de transformación de las obras del espíritu, Reus, Madrid, 2014, pág. 192.

17 STROWEL, A., Droit d'auteur et copyright, Bruylant, Bruxelles, 1993, pág. 100. 
donde autores como ARRAZOLA prestaron atención a la distinción entre forma y contenido ${ }^{18}$.

En efecto, al plantear sus tesis ${ }^{19}$ FICHTE distingue tres tipos de elementos en la propiedad de un libro, si bien apunta a que los razonamientos también serían extrapolables a otros tipos de obras: el libro como bien corporal (das Körperliche); el contenido del libro (das Materielle); y la forma de los pensamientos (die Form dieser Gedanken).

- Das Körperliche. Entendido como papel impreso, que pasa a ser de propiedad de quien lo compre, inmediatamente tras su venta. Al ser un objeto material, únicamente podría ser susceptible de apropiación por un solo individuo.

- Das Materielle. Son las ideas o pensamientos contenidos en el propio libro, que pasan a compartirse entre el autor y el público desde su publicación.

- Die Form dieser Gedanken. Sería la forma a través de la cual el autor exterioriza su pensamiento, que nunca dejará de ser propiedad exclusiva del autor, ya que no es posible adueñarse del pensamiento ajeno sin alterar su forma.

Posteriormente KOHLER sobre las distinciones elaboradas por FICHTE, da un paso más, postulando que dentro del elemento de la forma, sería necesario hacer una nueva distinción: la forma interna y la externa ${ }^{20}$.

La forma externa de KOHLER se asemeja a la forma (die Form dieser Gedanken) que ya había propuesto FICHTE. La novedad surge cuando habla de la forma interna, con la que favorece a los autores, al expandir el ámbito de protección del derecho de autor.

La influencia de las tesis propuestas por estos autores alemanes sigue presente en la actualidad. En la doctrina española, autores como BERCOVITZ RODRÍGUEZ-CANO, consideran que se ha de proteger tanto la forma como el contenido de las obras, principalmente porque en muchos casos resulta imposible distinguir entre ambos. Además, señala que existen determinados tipos de obras, tales como las narrativas (novelas, poesías, obras cinematográficas, teatrales, etc.) que precisan de esa doble protección, que abarcaría

18 ARRAZOLA, L., Enciclopedia española de Derecho y Administración o Nuevo Teatro Universal de la Legislación de España e Indias, Madrid, 1848, Tomo V, pág. 26.

19 FICHTE, J., Gesamtausgabe der Bayerischen Akademie der Wissenschaften, Stuttgart, 1964, págs. 407 y ss.

20 KOHLER, J., Urheberrecht an Schriftwerken und Verlagsrecht, Scientia, Aalen, 1980, pág. 129. 
aspectos tales como el argumento, los personajes, los ambientes o las escenas ${ }^{21}$.

En el mismo sentido, RODRÍGUEZ TAPIA considera que la forma interna de una obra y, por tanto, la idea que encierra, ha de ser susceptible de protección por el derecho de autor, de la misma manera que la forma externa de la obra. Pero matiza que la idea debe estar expresada, así como ser original y tener la suficiente complejidad, dejando de ser una mera abstracción, para poder ser susceptible de protección ${ }^{22}$.

La jurisprudencia de nuestro país también se ha hecho eco de la doctrina alemana, utilizando sus postulados para la resolución de litigios actuales. Un ejemplo, sería el de la SAP Madrid, Sección 28 de 17 de septiembre de $2015^{23}$, que resolviendo un caso de "transformación rayana en el plagio" que afectaba a Antena 3 y Telecinco por sus series "Aquí no hay quien viva" y "La que se avecina", señaló que: "en esta clase de obra adquiere particular consideración lo que, siguiendo a la doctrina alemana, se ha dado en llamar 'forma interna', como término diferenciado de la 'forma externa', consistente esta última en la exteriorización concreta de la obra y, aquella, en el modo en que se organiza y presenta el contenido, la conformación estructural de la obra o las principales características expresivas de la misma".

21 BERCOVITZ RODRIGUEZ-CANO, R., op. cit., nota 1.

22 RODRÍGUEZ TAPIA, J.M., "Comentario al artículo 10", en RODRÍGUEZ TAPIA, J.M. (dir.), Comentarios a la Ley de propiedad intelectual, $2^{\mathrm{a}}$ Ed., Thomson Civitas, Madrid, 2009, pág. 120.

${ }^{23}$ SAP Madrid, de 17 de septiembre de 2015 (ROJ: 13009/2015). La Audiencia Provincial de Madrid se pronunció sobre la reclamación de Antena 3 contra la serie de televisión "La que se avecina" de Telecinco. La demandante alegó que se había vulnerado la propiedad intelectual de la serie "Aquí no hay quien viva", además de la comisión de actos de competencia desleal. La Audiencia consideró que la serie "Aquí no hay quien viva", al ser una obra original y con cierta altura creativa, era merecedora de ser protegida por el derecho de propiedad intelectual. Sin embargo consideró que no podía calificarse a "La que se avecina" como una obra derivada de la anterior, con lo cual Telecinco no precisaba autorización de Antena 3. La Audiencia señaló que para que se pudiese apreciar una obra derivada no era suficiente con que existan elementos de conexión entre ambas series televisivas, sino que además era necesario que tales elementos fuesen esenciales y determinasen la singularidad de la obra originaria ("Aquí no hay quien viva") respecto al resto de obras del mismo género.Se consideró que no se produjo infracción de los derechos de propiedad intelectual, por cuanto las coincidencias existentes en el reparto artístico y técnico se consideraron irrelevantes, así como la trama, escenas, personajes, escenarios, etc. constituían 'Scènes à faire', es decir, situaciones inevitables, características de un género cinematográfico. 


\section{2. Los criterios para comprobar la conexión entre distintas obras}

Tenga un mínimo de originalidad y sea ésta o no la medida desde el contenido o la forma (incluida la forma interna), en la obra derivada han de producirse, necesariamente, una serie de elementos procedentes de una obra anterior, así como otros que aporten una novedad y por tanto, tengan altura creativa, originalidad. La falta de unos u otros conllevará a que no podamos decir que una obra es derivada y ello porque si hubiera demasiados elementos reproducidos de otra obra se correría el riesgo de que fuera su mera copia, es decir, un plagio de otra. Si por el contrario, en la nueva obra, hubiera pocos elementos de una obra anterior en la nueva, quizás no estaríamos ante una transformación, sino ante una inspiración de aquella, con lo cual la obra se consideraría igualmente tan original como la obra originaria.

Para poder dilucidar que no estamos en ninguno de los dos casos anteriores, existen una serie de instrumentos o criterios elaborados por la doctrina y la jurisprudencia, española y extranjera. No obstante, su aplicación no siempre es sencilla, a lo que tampoco ayuda que no exista un consenso generalizado sobre cuál sea el mejor.

En primer lugar, podríamos hablar del protected expression test (test de la expresión protegida), cuya finalidad sería asegurar que el autor de una obra originaria no se apropia de elementos contenidos en ésta, por ser, en realidad, de dominio público, pudiendo ser utilizados por otros autores ${ }^{24}$. Para este test lo relevante no sería analizar todos y cada uno de los elementos protegibles, sino una cantidad representativa que sirviera para determinar la existencia o no de una conexión entre la obra originaria y derivada.

Se trata de un instrumento que ha sido utilizado por los tribunales españoles ${ }^{25}$. Sin embargo, lo que sucede con este test, es que conduce a un análisis de tipo cuantitativo en el que se llegará a la conclusión de que hay más o menos similitud en función del número de elementos repetidos en ambas obras. Además, su aplicación es bastante limitada porque la similitud o conexión entre las obras únicamente se podría detectar en cuanto al aspecto externo de las

24 GOLDSTEIN, P., Copyright: Principles, Law and Practice, Vol. II, Ed. Little, Brown \& Company, Boston, 1989, págs. 22-30.

25 Son de destacar las siguientes sentencias: STS de 28 de enero de 1995 (ROJ: 359/1995); STS de 23 de marzo de 1999 (ROJ 2020/1999); y STS de 26 de noviembre de 2003 (ROJ 7529/2003). 
mismas, al prestar atención únicamente a la forma en la que se exteriorizan tales creaciones.

Por otro lado, cabría hablar del llamado substancial similarity test (test de la similitud sustancial), que ayuda a determinar si los elementos tomados de una obra, una vez identificados en otra obra, estarían protegidos por el derecho de autor ${ }^{26 .}$

Algunas variantes de este test son el Ordinary observer Test (Test del obervador medio) y el Extrinsic/Intrinsic Approach (enfoque extrínseco/intrínseco).

El test del observador medio es, en esencia, un test que se sirve de las impresiones de un observador u oyente ordinario, es decir, de una persona que no es experta en la materia. Lo que se le pide es que tras comparar dos o más obras, indique si a su juicio existen diferencias o, por el contrario su apariencia es la misma ${ }^{27}$.

Por su parte, el enfoque extrínseco/intrínseco, es el más extendido dentro de los enfoques o criterios para determinar la similitud sustancial entre obras por los tribunales federales de Estados Unidos. Para su aplicación, en primer lugar, se implementa la llamada prueba "extrínseca" (que podríamos identificar con la forma), en la cual el tribunal, con la asistencia de expertos, se encarga de identificar elementos que son protegibles o no protegibles, pasando a decidir si existe suficiente similitud con los elementos protegibles de la otra obra. En segundo lugar, se practicaría la prueba "intrínseca", en la que los miembros de un jurado, constituido por observadores legos, habrán de determinar si existe una similitud sustancial respecto al conjunto de la obra. En esta fase lo relevante es, pues, que se mida la similitud por personas medias, sin que quepa el análisis de expertos ${ }^{28}$.

Otro criterio distinto que cabría mencionar es el total concept and feel test ${ }^{29}$ (test de sensación de conjunto). Por medio de éste, se

26 GOLDSTEIN, P., op. cit., nota 7.

27 SPRINGMAN, C., and HEDRICK, S., The Filtration Problem In Copyright's "Substantial Similarity" Infringement Test, Lewis and Clark Law Review, Vol. 23, 2019, págs. 577-578.

28 SPRINGMAN, C., and HEDRICK, S., op. cit., nota 10.

29 La expresión total concept and feel, fue acuñada en una sentencia del Noveno Circuito de EEUU en el año 1970. No obstante, fue más tarde, en 1977 (en el caso Sid \& MartyKrofft Television Productions, Inc. v. McDonald's Corp.), cuando se convirtió en un criterio que sería aplicado en casos de derechos de autor, no solo por otros tribunales estadounidenses sino más tarde también por tribunales extranjeros. BRASHEARS-MACATEE, S., Total Concept and Feel or Dissection: Approaches to the Misappropriation Test of Substantial Similarity, Chicago-Kent Law Review, Vol. 68, 1992, págs. 918-919. 
llevaría a cabo la comparación de dos obras en busca de similitudes en sus elementos no literales, tales como la selección original, la coordinación y la disposición de las expresiones. La finalidad fundamental de este test sería que no se procediese de forma automática a diseccionar una obra, comparando únicamente elementos de forma separada, sino que por el contrario, se tratase de apreciar la similitud de una forma más global.

Uno de los casos donde se utilizó el total concept and feel test fue el caso de Litchfield v. Spielberg (Sentencia de la Corte de Apelación del Noveno Circuito de 6 de julio de 1984), que es bastante conocido por referirse a la película "E.T. El extraterrestre". La parte demandante consideró que la película era una transformación de su obra Lokey from Maldemar. Sin embargo, tras aplicar el total concept and feel test, el Tribunal estimó que no se podía apreciar una similitud sustancial entre las obras, por lo que ningún espectador ordinario hubiera podido relacionarlas ${ }^{30}$.

El último de los instrumentos, empleados por los tribunales estadounidenses, que mencionaremos es el denominado striking similarity (que traduciríamos como "similitud notable").

Como señala BARRETT, con frecuencia existen supuestos en los que esa similitud entre dos obras es tan "alto", que ese parecido o similitud únicamente puede ser indicativa de que una de las obras ha copiado contenido de la otra, y ello incluso sin existir otro tipo de pruebas. Evidentemente, tal supuesto sólo podría ocurrir cuando la obra originaria tuviera un grado de creatividad tan sumamente alto que la distinguiera de cualquier otra, de tal forma que el autor de la obra derivada nunca hubiera podido crear los mismos elementos de forma independiente o copiarlos de cualquier otra obra ${ }^{31}$.

En Europa, el equivalente a la doctrina de la strinking similarity lo ha proporcionado la doctrina francesa y la ha llamado capillarité de la propriété intellectuelle ${ }^{32}$. Esta "capilaridad" será posible de apreciar cuando elementos concretos de una obra ostenten un grado tan elevado de definición y originalidad, que sobresalgan de entre todos los demás que componen la misma obra.

30 BRASHEARS-MACATEE, S., Total Concept and Feel or Dissection: Approaches to the Misappropriation Test of Substantial Similarity, Chicago-Kent Law Review, Vol. 68, 1992, pág. 932.

31 BARRETT, M., Intellectual Property, Aspen Publishers, New York, 2008, pág. 129.

32 BERTRAND, A., Le Droit d'Auteur et les Droits Voisins, Masson, 1991, pág. 110.

(C) UNED. Revista de Derecho UNED, núm. 27, 2021 
Otro de los mecanismos europeos que cabría mencionar es el "test de los cinco pasos" empleado por la jurisprudencia alemana. Se trata de un test que tiene una doble finalidad. Por un lado, puede servir para analizar si concurren los requisitos para que una obra sea reconocida como creación original, y por otro, contribuye a diferenciar qué partes de una obra serán originales, en contraposición con los elementos que se hayan tomado de otras obras ya existentes.

La Ley alemana de derechos de autor y derechos conexos (Gesetz über Urheberrecht und verwandte Schutzrechte ${ }^{33}$ ) tradicionalmente ha utilizado un "test subjetivo de individualidad", es decir, una obra no está protegida simplemente porque surja del esfuerzo de un autor sino porque muestre rasgos de su personalidad e individualidad, es decir, una prueba subjetiva de originalidad. Según LÖWEN$\mathrm{HEIM}^{34}$, la Ley alemana exige que se reúnan una serie de requisitos para considerar que el contenido de una obra sea protegible, a saber: creación personal (persönliche Schöpfung), intelectualidad (geistigen Gehalt), expresión o fijación (Formgestaltung), individualidad (Individualität) y tener altura creativa (Gestaltungshöhe).

Por lo que atañe a la aplicación de este tipo de criterios por parte de los tribunales españoles, MARISCAL GARRIDO-FALLA, señala que no hay constancia de que se haya recurrido a un observador medio para que lleve a cabo valoraciones sobre posibles similitudes entre obras. Los tribunales, tal y como muestra la jurisprudencia, se han decantado siempre por el criterio de peritos, expertos en la materia objeto de examen en cada caso ${ }^{35}$.

\section{3. La autorización como requisito fundamental de la transformación}

Por lo que respecta al momento, nos podríamos plantear si es preciso que la autorización sea previa a la divulgación de la obra derivada o si por el contrario, cabría obtenerla posteriormente. Teniendo en cuenta que la eventual carga de la prueba recaerá sobre el

33 Disponible en WIPO Lex: https://wipolex.wipo.int/es/legislation/details/17676 (Última consulta 18 de mayo de 2020).

34 SCHRICKER, G. y LÖWENHEIM, U., Urheberrecht: Kommentar, 4th ed., CH Beck, 2010 § 2 para 9.

35 No obstante, MARISCAL GARRIDO-FALLA destaca que sí hay, al menos, un caso en el que un tribunal recomendó recabar la valoración de un consumidor medio, si bien en el litigio se utilizó el informe de un experto. SAP de Barcelona de 21 de junio de 2011. MARISCAL GARRIDO-FALLA, P., Derecho de transformación y obra derivada, Ed. Tirant Lo Blanch, Valencia, 2013, pág. 107. 
autor de la obra derivada, sería conveniente que la autorización se hubiera obtenido con anterioridad. No obstante, si la autorización se otorgara inmediatamente tras la explotación de la obra derivada, no existiría, en principio, ningún impedimento legal para ello. Esto es así porque la ley es bastante ambigua al indicar, únicamente, que se requiere la autorización del autor de la obra originaria, sin extenderse demasiado en las características y contenido de la misma ${ }^{36}$.

\section{3. A. Naturaleza de la autorización}

Es suficiente con el grado de originalidad que pueda apreciarse en la obra para considerar que estamos ante una obra derivada. Ya se dijo que mientras quede en la esfera privada del autor de la transformación, no surgirán problemas con el autor de la obra de la que derive.

Ahora bien, el hecho de que no exista una autorización no es un impedimento para la creación de la obra derivada, sí conllevaría la ilicitud de su explotación ${ }^{37}$. Si una vez que se ha creado la obra derivada el autor de ésta no consigue la autorización pertinente, únicamente tendría dos opciones: conformarse con que su obra nunca sea divulgada o bien esperar a que la obra originaria caiga en el dominio público para poder explotar, de esta manera, su obra.

En cualquier caso, la autorización del autor de la obra originaria tiene una gran trascendencia, ya que la acción de transformar una obra sin contar con la pertinente autorización, al margen de la responsabilidad civil, constituiría un delito, y como tal, acarrearía las consecuencias descritas en el art. 270. $1 \mathrm{CP}^{38}$.

36 RAMS ALBESA, J.: "Comentario al artículo 21 de la Ley de Propiedad Intelectual" en Comentarios al Código Civil y a las Compilaciones forales, (coord. M. Albaladejo) Tomo V, vol. 4º-B, Ed. Edersa, Madrid, 1994, pág. 342.

37 Existe unanimidad en la doctrina en cuanto a que la autorización es un requisito para que la explotación sea lícita, pero no para poder llevar a cabo su creación. "La obra no podrá ser utilizada lícitamente (y digo utilizada y no realizada porque la mera realización no puede impedirse, del mismo modo que no se impide leer el libro y copiarlo para uso propio) sin el consentimiento del autor o de sus derechohabientes mientras dure el correspondiente derecho". ASCARELLI, T. Teoría de la concurrencia y de los bienes inmateriales", Ed. Bosch, Barcelona, 1970, pág. 651.

38 Art. $270.1 \mathrm{CP}$ : "Será castigado con la pena de prisión de seis meses a cuatro años y multa de doce a veinticuatro meses el que, con ánimo de obtener un beneficio económico directo o indirecto y en perjuicio de tercero, reproduzca, plagie, distribuya, comunique públicamente o de cualquier otro modo explote económicamente, en todo o en parte, una obra o prestación literaria, artística o científica, o su transformación, interpretación o ejecución artística fijada en cualquier tipo de soporte o comunicada a

(C) UNED. Revista de Derecho UNED, núm. 27, 2021 
Así se desprende de la necesaria la autorización de su explotación por parte del autor de la obra preexistente que exige el TRLPI (ex. Art. 17). Corresponde al autor de la obra originaria el ejercicio en exclusiva de los derechos de explotación, lo que significa que, como consecuencia directa de ese precepto, será el autor el único sujeto legitimado para decidir qué tipos o formas de explotación podrán llevarse sobre su obra, o si por el contrario, no se explota de ninguna manera. Se observa así que los derechos de explotación poseen una doble faceta, una positiva y otra negativa ${ }^{39}$. Corroborando lo mismo, pero en sede del derecho de transformación y por tanto, regulando el derecho de explotación correspondiente al autor de la obra derivada, el art. 21 TRLPI, reconoce la existencia de derechos a los autores de la obra originaria, objeto de transformación, sobre la derivada, lo que se justifica porque como afirma MAYOR DEL HOYO, la obra derivada surge, parcialmente, por haber utilizado el esfuerzo creativo del autor de la obra originaria ${ }^{40}$.

Y aquí surge uno de los aspectos singulares que presenta el ejercicio del derecho de transformación es que el autor de la obra objeto de transformación deberá por un lado, consentir la realización de la transformación y por otro, consentir la explotación del resultado de dicha transformación.

Parece que el sujeto que pretenda transformar una obra debería contar con dos autorizaciones: la primera para realizar la actividad transformadora y la segunda para realizar la explotación de la obra derivada de la transformación. Sin embargo, tal y como señala MARISCAL GARRIDO-FALLA ${ }^{41}$, tanto en el ámbito nacional como en el extranjero ${ }^{42}$ la doctrina mayoritaria es partidaria de entender

través de cualquier medio, sin la autorización de los titulares de los correspondientes derechos de propiedad intelectual o de sus cesionarios".

39 Como apunta SÁNCHEZ ARISTI, "así como puede prohibir que otros sujetos realicen una actividad de explotación que afecte a su obra, el autor es el único que puede permitir o consentir que otros realicen dicha explotación. La expresión que ha hecho fortuna para describir ese control conferido en exclusiva al autor es la de que éste goza de un derecho de autorizar o prohibir o, en fórmula aún más sintética, de un ius prohibendi". SÁNCHEZ ARISTI, R., "Comentario al art. 17", en Comentarios a la Ley de Propiedad Intelectual (coord. R. Bercovitz Rodriguez-Cano), $4^{\mathrm{a}}$ ed., Tecnos, Madrid, 2017, pág. 302.

40 MAYOR DEL HOYO, M.V., La obra cinematográfica derivada de otra obra cinematográfica: remakes, segundas o sucesivas partes y otros supuestos. Revista Aranzadi de Derecho patrimonial (16). 2006, pág. 83.

41 MARISCAL GARRIDO-FALLA, P., "Comentario al art. 21", en Comentarios a la Ley de Propiedad Intelectual (coord. R. Bercovitz Rodriguez-Cano), $4^{\mathrm{a}}$ ed., Tecnos, Madrid, 2017, pág. 456.

42 La doctrina francesa, por ejemplo, sigue esta línea. DESBOIS, H., Le droit d'auteur en France, $3^{\mathrm{a}}$ ed., Dalloz, París, 1978. pág. 745, señaló al respecto: “¿por qué 
la autorización para transformar como si en realidad se tratase de una autorización para explotar la obra derivada. Esta corriente doctrinal consideraría que "es precisamente la explotación ad extra de la obra transformada la que requiere del consentimiento de su titular, y no el acto de transformación previo, que debería quedar dentro de la esfera privada de cada sujeto". En la misma línea, RIVERO HERNÁNDEZ señalaba que "la autorización comporta no sólo la mera transformación (que en sí misma, como actividad no es ilícita: piénsese en una traducción como ejercicio literario o lingüístico), sino la de explotación de la obra derivada" ${ }^{43}$.

Se puede afirmar, por tanto, que existe un consenso en cuanto a que las transformaciones que un sujeto lleve a cabo en el ámbito privado, al ser de imposible control, y al no haber actividad de explotación, carecerán de importancia al no llegar a divulgarse y no existir, en definitiva, ánimo de lucro ${ }^{44}$. No obstante, a pesar del citado consenso actual, la inocuidad de las transformaciones en el ámbito privado no fue siempre considerada como tal, exigiéndose la autorización expresa para llevar a cabo el acto transformador incluso si no había explotación posterior ${ }^{45}$.

un escritor consiente la adaptación teatral de una de sus obras? Sería paradójico considerar que por regla general se contenta con ofrecer una ocupación a un dramaturgo ocioso, o de proporcionarle la ocasión de entregarse a un ejercicio que no será seguido de una puesta en escena. La presunción contraria parece oportuna y pertinente, pues una novela está destinada a ser leída y una pieza de teatro a ser interpretada; la vocación de toda obra, originaria y derivada, es hacerse llegar al público?"

43 RIVERO HERNÁNDEZ, F., "Comentario al art. 21", en Comentarios a la Ley de Propiedad Intelectual (coord. R. Bercovitz Rodriguez-Cano), $3^{\mathrm{a}}$ ed., Tecnos, Madrid, 2007, págs. 379-378.

${ }_{44}$ En esta misma línea LÓPEZ SÁNCHEZ señala que "salvo si dicha explotación se realiza en circunstancias que supongan su divulgación, puede tratarse de un acto estrictamente privado que queda a extramuros del derecho de autor. Así pues, el titular del derecho de transformación puede autorizarla o prohibirla, pero no impedir que alguien la realice sin el propósito de explotar o difundir el resultado, de manera que la protección no alcanza los usos privados". LÓPEZ SÁNCHEZ, C., La transformación de la obra intelectual, Dykinson, Madrid, 2008, pág. 90.

${ }_{45} \mathrm{Al}$ respecto cabe mencionar un caso mediático en España, en el que el escritor Manuel Vázquez Montalbán fue condenado por el Juzgado de Primera Instancia de Barcelona en concepto de perjuicio moral, por utilizar partes de una traducción de la obra Julio César, de Shakespeare, previamente realizada por el profesor de la Universidad de Murcia, Ángel Luis Pujante. El caso llegó hasta el Tribunal Supremo, que señaló que: "si bien es cierto que nada impide a un autor tener en cuenta para la creación de su obra, el contenido de otras anteriores, que pueden influir en el contenido de la nueva, tal consideración no permite suponer que el nuevo autor se halle facultado para incorporar a su obra una parte mayor o menor de aquélla, sin autorización del primitivo autor", añadiendo a lo anterior que "obviamente esta última conclusión no se desnaturaliza por el hecho de que el demandado reconociera públicamente haber utilizado en su adaptación teatral la traducción

(C) UNED. Revista de Derecho UNED, núm. 27, 2021 
Una posible evidencia de que en la práctica actual y en la mayoría de los contratos se produce una superposición de ambos consentimientos (para transformar la obra originaria y para poder llevar a cabo la explotación de la obra surgida de la transformación), se encontraría en el hecho de que cuando el autor de la obra originaria concede la autorización para llevar a cabo la explotación de la obra derivada, la retribución fijada en el contrato de transformación dependerá, normalmente, de los ingresos que tengan su origen en la propia actividad de explotación ${ }^{46}$.

\section{3. B. Sujetos legitimados y formalidades para prestar la autorización}

Dejamos a un lado el análisis de los requisitos generales del consentimiento negocial y recordamos con RIVERO HERNÁNDEZ ${ }^{47}$ que la autorización del autor tiene una clara apariencia de consentimiento negocial. En la mayoría de las ocasiones se presentará como parte integrante en un contrato (de edición, de representación escénica, de exposición, de enajenación de la obra de arte plástica...), conteniéndose en aquel, pues, de forma implícita. Sin embargo, en otros casos formará parte de la naturaleza y caracteres del acto específico.

Preferimos entrar en la manera en la que deba prestarse el consentimiento, y partir de que no existe ninguna formalidad concreta exigida por la ley para la obra de transformación; por lo que en cuanto a la forma, la aplicación del art. $45 \mathrm{TRLPI}^{48}$ que señala que toda cesión deberá realizarse por escrito es común a cualquier tipo de obra pues se configura como una exigencia que se establece en bene-

realizada por el demandante, pues, ni tal incorporación se realizó a título de cita o para su análisis, comentario o juicio crítico, por lo que no puede predicarse su licitud, por virtud de lo prescrito en el artículo 32 de la repetida Ley de Propiedad Intelectual, ni menos aún podría admitirse que, a espaldas de dicho precepto, el simple reconocimiento, incluso público, de estarse utilizando una obra anterior, permita, cuando no se cuente con la autorización de su autor, la reproducción total o parcial de la misma, permitiéndose con ello burlar los derechos intelectuales del mismo". STS (Sala de lo Civil), núm. 1268/1993, de 29 diciembre de 1993. (RJ 1993/10161).

46 AYLlÓN SANTIAGO, H., El derecho de transformación de las obras del espíritu. Reus. Madrid. 2014. pág. 192.

47 RIVERO HERNÁNDEZ, F., "Comentario al art. 17", en Comentarios a la Ley de Propiedad Intelectual (coord. R. Bercovitz Rodriguez-Cano), $3^{\text {a }}$ ed., Tecnos, Madrid, 2007, págs. 304-305.

48 Art. 45 TRLPI: "Toda cesión deberá formalizarse por escrito. Si, previo requerimiento fehaciente, el cesionario incumpliere esta exigencia, el autor podrá optar por la resolución del contrato". 
ficio del autor de la obra originaria, y es irrenunciable, en los términos del art. 55 TRLPI.

Pero resulta llamativo que el citado art. 45 TRLPI, al hablar del incumplimiento del requisito formal, únicamente contemple que lo pueda realizar el cedente y que no se pronuncie sobre las consecuencias que habría para el cesionario. Trasponiendo este artículo a la materia concreta que a continuación trataremos, es decir, la secuela, habría que entender que cuando se habla del "autor", lo sería el de la obra originaria, mientras que el "cesionario" sería el autor de la obra derivada (secuela).

Haciendo un análisis interpretativo del precepto, si el sujeto incumplidor del requisito de la forma escrita fuese el autor de la obra originaria, no parece que pudiera haber impedimento alguno para que la obra derivada pudiera subsistir, si bien, el autor de la misma, en caso de ser necesario, deberá probar que existió la cesión, valiéndose para ello de los distintos medios admitidos en derecho. Por el contrario, si quien incumple es el autor de la obra derivada (el cesionario), operaría el mecanismo previsto en el propio art. 45 TRLPI, es decir, el autor de la obra originaria, previo requerimiento fehaciente al cesionario para que se plasmara por escrito la cesión, podría optar por la resolución del contrato de cesión, cuando aquel se negase a cumplir con la formalidad impuesta por la ley.

Para TORRES LANA ${ }^{49}$, la fórmula que ha empleado el legislador en el art. 45 TRLPI es similar a la que el Código Civil utiliza en su art. 1.280, es decir, a pesar de que en el art. 45 TRLPI se utilice la expresión "deberá formalizarse por escrito", al igual que el art. 1.280 $\mathrm{Cc}$, esto no sería un obstáculo para que si las partes quisieran celebrar un contrato de cesión, obviando la forma escrita, no se impediría que se produjesen plenos efectos. Por tanto, la imposición legal de forma escrita tendría un carácter ad probationem, si bien existirían distintas consecuencias para el autor de la obra originaria y el de la obra derivada, como ya se ha expuesto anteriormente.

Sin embargo, no compartimos la anterior posición y es que, en efecto, la importancia de que conste el acuerdo por escrito entre las partes es tal que afectaría a la propia existencia del contrato de cesión. Así lo ha manifestado también la jurisprudencia, en sentencias tales como la de la AP de Alicante de 19 de junio de $2006^{50}$, que se-

49 TORRES LANA, J.A., “Comentario al art. 45”, en Comentarios a la Ley de Propiedad Intelectual (coord. R. Bercovitz Rodriguez-Cano), $4^{\mathrm{a}}$ ed., Tecnos, Madrid, 2017, págs. 896-898.

50 SAP Alicante de 19 junio de 2006 (EDJ 2006/289675). 
ñaló que: "no consta que cediera el actor sus derechos sobre las fotografías de manera extensiva y para todos aquellos eran susceptibles de ser cedidos, lo que desde luego no se puede presumir, al punto que el TRLPI -art.45- requiere de formalización escrita, señalando el artículo 43 que los derechos de explotación de la obra trasmitida por actos inter-vivos, queda limitada a cesión del derecho derechos concretamente cedidos, a las modalidades de explotación expresamente previstas y por el tiempo y ámbito territorial que se determinen, estableciéndose en el párrafo segundo de ese precepto las presunciones en defecto de pacto expreso".

\section{LA SECUELA COMO RESULTADO DE LA TRANSFORMACIÓN LLEVADA A CABO SOBRE LOS ASPECTOS ESTRUCTURALES DE LA OBRA}

El derecho de transformación constituye una materia compleja dentro de los derechos de autor. El motivo es que comprende actividades de naturaleza muy dispar: traducciones, adaptaciones y cualquier otra modificación en la forma de una obra de la que se derive otra obra diferente (arts. 11 y 21 TRLPI).

El enunciado de obra del art. 11 TRLPI, no es exhaustivo y responde o es fruto del histórico vivido en el reconocimiento progresivo de la protección de las obras derivadas necesitadas de protección intelectual. Por eso enuncia, como obras derivadas, las traducciones y adaptaciones; las revisiones, actualizaciones y anotaciones; los compendios, resúmenes y extractos; los arreglos musicales; y no cierra la protección dejando la expresión cualesquiera transformaciones de una obra literaria, artística o científica como cajón de sastre, de tal suerte que cualquier obra derivada que no encontrase encaje en una de las categorías expresamente mencionadas por el legislador, se ubicaría en esa última.

Pues ese es el encaje de la secuela que, al igual que cualquier obra derivada no se encuentra como apunta MARISCAL GARRIDOFALLA $^{51}$, sujeta a un tipo o género determinado de obras. Así, una obra derivada que encaje en el tipo "secuela" podría consistir, tomando los ejemplos de obras derivadas que hace el autor en "unos arreglos musicales, una segunda parte de una película, la adaptación cinematográfica de una novela, el paso de prosa a verso de un texto,

51 MARISCAL GARRIDO-FALLA, P., "Comentario al art. 11", en Comentarios a la Ley de Propiedad Intelectual (coord. R. Bercovitz Rodriguez-Cano), $4^{\mathrm{a}}$ ed., Tecnos, Madrid, 2017, pág. 198. 
la escultura que se crea a partir de una fotografía, la terminación de una obra inacabada, la actualización de un artículo doctrinal, la traducción de un texto, la creación de una serie de televisión a partir de una obra dramática, la reorganización de una base de datos, la elaboración de una antología de poesía... los ejemplos son numerosísimos"; aunque, como también apuntaremos, la secuela es más propia de las obras literarias o cinematográficas, donde la utilización de los elementos de una obra originaria son más variados y con ello los posibles autores a proteger.

Lo importante es que encaje en la originalidad que se presupone existe en la obra derivada. Recordemos con BERCOVITZ RODRÍGUEZ-CANO, que la obra derivada es fruto de la transformación de una obra preexistente, si bien ha de reunir los mismos requisitos que se le exigen con carácter general a todas las obras. La importancia de que la obra derivada consiste en que es una creación original aunque deriven, procedan o nazcan de la transformación de otra obra (artículos 11 y 21 TRLPI) preexistente ${ }^{52}$. Y una vez que tenemos originalidad, la especie en que consistiría la secuela dentro del genero de la obra derivada y que la hará diferenciarse del elenco no exhaustivo de obras citadas o encuadrables también en cajón de sastre del art. 11 TRLP, dependerá del grado de originalidad que la caracterize; y adelantamos, antes de pasar a encuadrarla en el momento histórico en que aparece, que la originalidad que caracteriza la secuela será máximo.

\section{1. Orígenes de la secuela}

Cuando se plantea la cuestión de qué es una secuela, suele ser habitual pensar en alguna segunda o tercera parte de una película, es decir, se tiende a encuadrar esta figura en el ámbito audiovisual. Esto no es de extrañar, ya que incluso cuando se trata esta figura por parte de la doctrina especializada en derecho de autor, se suele hacer en el contexto de adaptaciones cinematográficas de obras, asociándola con una amalgama de figuras que, si bien pueden presentar ciertos rasgos parecidos, sus consecuencias prácticas y jurídicas son diferentes, como se tratará más adelante.

Sin embargo, las secuelas no pueden quedar relegadas al ámbito audiovisual. De hecho, las primeras secuelas surgen mucho antes,

52 BERCOVITZ RODRIGUEZ-CANO, R., "Comentario al art. 10", en Comentarios a la Ley de Propiedad Intelectual (coord. R. Bercovitz Rodriguez-Cano), $4^{\mathrm{a}}$ ed., Tecnos, Madrid, 2017. pág. 191. 
en el ámbito literario. Es en el llamado Siglo de Oro, favorecido por el auge de la imprenta, cuando la práctica de continuar los trabajos literarios de otros autores alcanza a la totalidad de los ámbitos de la novela, desde la caballeresca hasta los relatos picarescos y la novela pastoril. La continuación de la más célebre obra de la literatura española, el Quijote, puede servir para ilustrar la práctica de la secuela. En efecto, su secuela (no autorizada) se trata de una obra que, publicada en $1614^{53}$, constituye un acontecimiento importante en la historia de la continuación ${ }^{54}$.

No obstante, lo llamativo es que esa segunda parte del Quijote se publica mientras Cervantes trabajaba también en la continuación de su primera obra, por lo que aprovecha para introducir alusiones a su derecho exclusivo para continuar la historia ${ }^{55}$, lo que constituye la postulación de ideas innovadoras en materia de autoría, que no se materializarían hasta siglos más tarde ${ }^{56}$. En efecto, durante el siglo de oro los autores no disponían de mecanismos para impedir las continuaciones de sus obras. No puede hablarse aún de un derecho de autor, existiendo tan solo los llamados "privilegios de impresión", por medio de los que los editores, durante un plazo limitado, podían imprimir los libros en determinados territorios ${ }^{57}$.

Como apunta HINRICHS, se podría decir que la obra de Cervantes no puede considerarse únicamente como la obra que definirá la novela, sino también la secuela. Las obras que van apareciendo en

53 Esta secuela no autorizada se publicó con el siguiente título: «Segundo tomo del ingenioso hidalgo don Quixote de la Mancha, que contiene su tercera salida; y es la quinta parte de sus aventuras. Compuesto por el Licenciado Alonso Fernández de Avellaneda, natural de la villa de Tordesillas».

54 La publicación en 1614 del Quijote de Avellaneda, "marca un hito en la historia de la continuación y puede servir eficazmente de botón de muestra, por varias razones: por una parte, es representativa de una práctica bien anclada en España, de la que condensa de forma extrema muchas características; y, por otra, constituye un punto de inflexión en la medida en que suscita por parte del autor primigenio una reacción inédita, que refleja de forma anticipada un cambio de sensibilidad en cuanto a la concepción de la autoría”. ÁLVAREZ ROBLIN, D. y BIAGGINI, O., La escritura inacabada: continuaciones literarias y creación en España: siglos XIII a XVII, Ed. Casa de Velázquez, Madrid, 2017, pág. 2.

55 Para mí solo nació don Quijote, y yo para él: él supo obrar y yo escribir, solos los dos somos para en uno, a despecho y pesar del escritor fingido y tordesillesco que se atrevió o se ha de atrever a escribir con pluma de avestruz grosera y mal delinéada las hazañas de mi valeroso caballero, porque no es carga de sus hombros ni asunto de su resfriado ingenio, afirmaría CERVANTES SAAVEDRA, M., Don Quijote de la Mancha, II, págs. 1105-1106.

56 ÁLVAREZ BARRIENTOS, J., (2006), Los hombres de letras en la España del siglo XVIII. Apóstoles y arribistas, Ed. Castalia, Madrid, 2006, págs. 244-256.

57 BAYLOS CORROZA, H., Tratado de Derecho industrial, $2^{\mathrm{a}}$ ed., Civitas, Madrid, 1993, págs. 161-164. 
España tienen una relevancia indudable en la invención de la secuela. Por este motivo se puede destacar la continuación literaria en las letras españolas como una práctica no solo coherente, teniendo en cuenta factores socioculturales de la época, sino que además antecede a otras obras que presentarán rasgos de secuela en Inglaterra y en Francia ${ }^{58}$.

\section{2. Consideraciones terminológicas}

Tras haber abordado la ubicación de la secuela en el cajón de sastre de las obras derivadas del art. 11 TRLPI y su ámbito de aplicación a cualquier obra del espíritu, antes de proceder a su conceptuación, se hace necesario abordar aspectos terminológicos de la palabra secuela que van apareciendo según el momento histórico que se considere, el medio en que nos movamos o el momento temporal en que extienda, desarrolle o continúe la obra originaria. Sin embargo, hay que señalar a priori, que no tenemos una definición legal de secuela, ya que ni los textos jurídicos nacionales ni los extranjeros ofrecen definición de ella.

La propiedad intelectual ha existido en todos los tiempos, sin embargo no ha sido objeto de regulación, desde su origen, por parte de la legislación positiva ${ }^{59}$. Este es el principal motivo por el que el derecho de transformación tardó en ser tratado de manera singularizada dentro del derecho de autor.

En efecto, el derecho de transformación no nace con la primera regulación de los derechos de autor ${ }^{60}$, sino más tarde, en 1858 , con

58 HINRICHS, W., "La novela y la secuela. De cómo la prosa narrativa del siglo de oro inventó la continuación literaria", en La escritura inacabada: continuaciones literarias y creación en España: siglos XIII a XVII, (eds. Álvarez Roblin, D. Y Biaggini, O.), Ed. Casa de Velázquez, Madrid, 2017, pág. 21.

59 POUILLET, E., Traité théorique et practique de la propriété littéraire et artistique et du droit du représentation, 3 ème édition, Ed. Marchal, Billard et Ce., Paris, 1879 , pág. 1-2.

60 La doctrina mayoritaria sitúa la concepción moderna del derecho de autor en 1709, fecha en la que se promulgó el Estatuto de la Reina Ana en Inglaterra. Este documento supuso un hito, al reconocerse al autor el derecho de copia sobre sus obras (copyright en inglés). El Estatuto otorgaba al autor el derecho exclusivo de reproducción sobre su obra por el periodo de 14 años, pudiéndose prorrogar por otro plazo igual, si el autor seguía con vida. Transcurrido ese plazo, los impresores o editores podían imprimirla, reimprimirla o importarla sin necesidad de autorización del autor. En el ámbito de protección otorgado por el Estatuto no se contemplaba aún el derecho exclusivo de transformación. Las traducciones y el resto de obras derivadas se protegían como si de obras originales se trataran, sin que surgieran cuestiones legales entorno al autor de la obra originaria y el autor de la obra derivada.

(C) UNED. Revista de Derecho UNED, núm. 27, 2021 
ocasión del primer Congreso Internacional para los derechos de autor $^{61}$. Lo que motivó la celebración de este Congreso fue, principalmente, la preocupación de sus promotores, muchos de ellos escritores, para que se reconociera de manera internacional la propiedad de las obras literarias y artísticas, así como la fijación temporal de los derechos de autor.

No obstante, la expresión "derecho de transformación" fue utilizada por primera vez en el Tratado celebrado entre Francia y Prusia el 2 de agosto de 1862. Según éste, el autor podía impedir durante cinco años la publicación de toda traducción no autorizada por él, pero bajo la condición de que hubiera indicado en el encabezado de su obra la intención de guardarse el derecho de traducción y que hubiera utilizado ese derecho siempre que permitiera una traducción autorizada en el plazo de un año, al menos de una parte y, en el plazo de tres años la totalidad; Además, era necesario realizar un trámite de registro para la obra original y la traducción. No obstante, incluso si el autor cumplía esos trámites, la obra era protegida sólo durante 5 años a partir de la publicación de la traducción ${ }^{62}$.

De esta manera se observa que es a partir los siglos XIX y XX, donde se va conformando el actual derecho de transformación.

Por lo que respecta, sin embargo, al término "secuela", cabe decir que serán los escritores y lingüistas los que nos dotarán de la terminología apropiada para referirnos a aquella, como subespecie de la obra derivada. Otra cosa es que no sea unánime que dicho vocablo se refiera siempre a los dos campos de actuación en los que preferentemente actúa: la obra literaria y la obra cinematográfica y que se hayan conformado con su raíz otros vocablos que, a ella, como término que designa una clase de obra en transformación, se refieran.

Para el HINRICHS ${ }^{63}$, el empleo de la palabra anglófona "secuela" con el significado de "continuación literaria" es relativamente reciente en la lengua española, y considera que su uso se circunscribe

61 El Congreso se estructuró en cinco secciones, cada una con una temática específica. Se trataron cuestiones como el reconocimiento internacional de la propiedad literaria y artística; la duración del derecho de autor y su naturaleza jurídica; la traducción y sus aspectos formales; así como la representación y ejecución pública de las obras dramáticas y musicales. CAVALLI, J., La genèse de la Convention de Berne pour la protection des oeuvres littèraires et artistiques du 9 de septiembre 1886, Imprimeries Réunies, Lausanne, 1986, págs. 90-107.

62 Actes de la Confèrence rèunie à Berlin du 14 Octobre au 14 Novembre 1908 avec les Actes de Ratification. Bureau de l'Union Internationale Littéraire et Artistique, Berne, 1910, pág. 245.

63 HINRICHS, W., op. cit., nota 29. 
fundamentalmente al cine, siendo por ello, en cierto sentido, un calco de la palabra inglesa sequel. No obstante, en el Diccionario de la $\mathrm{RAE}^{64}$ la definición de secuela tiene en cuenta en su tercera acepción la posibilidad la continuación de una obra tanto en el ámbito literario como cinematográfico. La define como una "obra literaria o cinematográfica que 'continúa' una historia ya desarrollada en otra anterior"65.

Resulta peculiar cómo se llegó a la creación y empleo de los términos anglosajones "precuela"66, e "intracuela" ; el primero para hacer referencia a aquellas historias que son creadas tras una obra originaria, pero que sitúan la acción en un momento anterior a la misma y el segundo, última importación terminológica sobre todo por la influencia de la industria del cine, en donde la continuación de la obra se desarrollaría en un momento cronológicamente intermedio respecto a la obra originaria o bien, cuando tiene lugar entre la originaria y su continuación.

Debido a su uso generalizado, la RAE incorporó el término "precuela" a su Diccionario en el año 2014, definiéndola como: "Obra literaria o cinematográfica que cuenta hechos que preceden a los de otra obra ya existente".

Pero si algo ha de quedar claro en cuanto al aspecto terminológico al que nos referimos, es que, por más que se adopten nuevos términos como precuela o intracuela, no dejarán de ser lo que son:

64 Vid. https://dle.rae.es/secuela?m=form (Última consulta 18 de mayo de 2020).

65 A pesar del empleo por nuestra Real Academia del término secuela por influencias anglosajonas, hay que destacar que dicha palabra viene del latín (sequela), y tenía, como apunta SEGURA, un significado igual al de ahora: "consecuencia o resulta de algo". En la palabra sequela se comprende el verbo sequ (seguir), que también se emplea como raíz en otras voces que derivan del mismo y, que guardan en cierto modo relación con el mismo. Algunos ejemplos podrían ser "consecuente", "secuencia" o "séquito". No es de extrañar pues, que con la aparición de otras novelas y, más tarde películas, en las que se retomase la historia de las precedentes se popularizara la utilización del término "secuela" para denominar a las segundas, terceras o sucesivas partes de aquellas. Vid. SEGURA, S., Lexicón etimológico y semántico del Latín y de las voces actuales que proceden de raíces latinas o griegas [incompleto], Universidad de Deusto, Bilbao, 2014, pág. 694.

66 Como señala ALVAR EZQUERRA con el término "precuela" se ha producido una segmentación equívoca del vocablo como consecuencia de separar se y cuela, para cambiar la primera sílaba por el prefijo pre-. Esta forma peculiar de crear el término surgió, sin embargo, en la lengua inglesa, de donde se exportó al castellano. De no haberse producido tal exportación, quizás hubiera sido más adecuada la adopción de otros términos tales como "antecedente", "ante-relato" u otros similares de los que disponemos en nuestra lengua. ALVAR EZQUERRA, M., Lo que callan las palabras. Mil voces que enriquecerán tu español, JdeJ Editores, Madrid, 2014, pág. 231.

(c) UNED. Revista de Derecho UNED, núm. 27, 2021 
secuelas. Se continúen por delante o por el medio, su creación siempre es posterior.

\section{3. Concepto}

Partiendo del estatus de la secuela como obra derivada y teniendo en cuenta que se adopten o no términos derivados de ella en función de si continúan la obra original desde donde ésta finaliza o desde donde se inicia, cuando entramos ya en la búsqueda de su definición, lo primero que observamos es que el concepto varía según se tenga en mente una secuela literaria o bien una audiovisual. No obstante, sea en el medio que sea, puede decirse que la secuela consistirá en lo mismo: prolongar o continuar una obra previa.

Una primera aproximación al concepto podría ser la ofrecida por NAVAS NAVARRO, quien define la secuela desde una perspectiva audiovisual como "la continuación de una obra anterior debido a la continuación del argumento, o a la elaboración de otra historia que toma los elementos y las señas de identidad de la primera obra audiovisual de manera que se pueda establecer un lazo entre ambas, lo que aleja la segunda obra de la versión libre ${ }^{67 "}$.

Para LACOMBA ${ }^{68}$ "una continuación lo es con respecto a algo, supone un vínculo con un origen, lo cual implica una relación de dependencia, de subordinación cronológica".

Las secuelas constituyen obras que, además, según LY se pueden considerar como "reveladoras de un canon narrativo ya que promueven modelos a seguir, aunque también los discutan y modifiquen". Al continuar obras pretéritas, las secuelas también sirven como instrumento de estudio de la historia de la literatura o del cine, y ello porque "al plagiar, violar, traicionar obras originarias o al adaptarse gozosamente a ellas, demuestran que existen verdaderas poéticas del préstamo, del plagio, del fraude, como existen "poetas de poetas», cuyos versos tejen ecos y recuerdos de versos remotos o contemporáneos, siempre ajenos, componiendo conjuntos paradójicamente propios y absolutamente nuevos" 69 .

67 NAVAS NAVARRO, S., "La obra audiovisual derivada", Anuario de Propiedad Intelectual, Ed. Reus-Aisge, Madrid, 2003, pág. 301.

68 LACOMBA, M., "El Cid ha muerto, viva el Cid. De la continuidad a la continuación", en La escritura inacabada: continuaciones literarias y creación en España: siglos XIII a XVII, (eds. Álvarez Roblin, D. y Biaggini, O.), Ed. Casa de Velázquez, Madrid, 2017, págs. 105-106.

69 LY, N., "Conclusiones", en La escritura inacabada: continuaciones literarias y creación en España: siglos XIII a XVII, (eds. Álvarez Roblin, D. y Biaggini, O.), Ed. Casa de Velázquez, Madrid, 2017, pág. 261. 
En vista de lo anterior, podríamos afirmar, pues, que el rasgo definitorio de la secuela sería por un lado, la "continuación", y por otro, la "dosis de originalidad", que tendrá que ser, tal y como se ha señalado, la justa para no caer en plagio o convertirse en una obra totalmente independiente.

\section{FIGURAS SIMILARES}

Existen una serie de obras, algunas de ellas con gran relevancia en el campo audiovisual, que si bien no constituyen una secuela (entendida como la continuación de otra obra), sí que presentan características similares y, tendrán consecuentemente el mismo tratamiento por parte del legislador en el TRLPI. Nos referimos a figuras tales como el remake y el spin off. Ambas entrarían, a nuestro entender, en lo que anteriormente denominamos como cajón de sastre. El tratamiento que se hace es, en todo caso, un ejercicio de teorización por parte de la doctrina, al no existir, por el momento, un tratamiento jurisprudencial de las mismas.

Caso aparte sería la parodia, que a pesar de presentar algunas similitudes con la secuela, no será objeto de tratamiento aquí, al necesitar un estudio más profundo ${ }^{70}$.

\section{1. El remake}

El término remake, de procedencia anglosajona, se trata de una palabra muy utilizada y, una clara consecuencia de ello es que en España se utilice con total normalidad, sin intentar, tan siquiera, buscar una traducción. Sin embargo, si se procediese a traducir este término al castellano, literalmente significaría "volver a hacer". Y, aun así, tal traducción, no nos permitiría tener una imagen concisa del significado de esta figura, en relación con los derechos de autor.

70 Esta figura se perfila como un límite a los derechos de autor. En efecto, conviene prestar atención a la sistemática escogida por el legislador. La parodia se encuentra recogida en el art. 39 TRLPI, situado en el Capítulo II, del Título III, donde se regulan una serie de límites a los derechos de autor, en contraposición a la regulación de las obras derivadas y el derecho de transformación (arts. 11 y 21, respectivamente, Título II).

No obstante, la parodia debe ser una obra en sí misma y, no solo la práctica de meros retoques o alteraciones irrelevantes sobre la obra parodiada, como señala PERDICES HUETOS, A.B., "La muerte juega al Gin Rummy (la parodia en el derecho de autor y de marcas)" en Revista de Propiedad Intelectual, núm. 3/1999, pág. 23. 
Lo anterior, también ha sido apuntado por autores como ÉCIJA BERNAL, que señala que el término remake, es una expresión anglosajona que no tiene una traducción satisfactoria a nuestro idioma y apunta que es lo que normalmente se conoce como "versión". Además, este tipo de obras, una especie de "autofagia audiovisual' ${ }^{71}$, se da cada vez con más frecuencia, debido a la escasez de ideas o tal vez al miedo a arriesgarse con proyectos nuevos ${ }^{72}$. Esa necesaria similitud argumental se plasma con mucha claridad por PÉREZ DE CASTRO, quien invita a la siguiente reflexión: "Piénsese en películas como 'Crimen perfecto' y 'Titanic'. En ellas el espectador que acude a las salas de cine ya tiene conocimiento de los personajes, de la historia que se desarrolla y del desenlace de la misma. Ahora bien, existen variaciones entre la primera obra y la versión de la misma, no sólo en cuanto a los intérpretes, sino también por la introducción de los nuevos medios técnicos que pueden hacer más reales las situaciones, como en el caso de 'Titanic' o la introducción de nuevos elementos en los personajes, como en el supuesto de 'Crimen perfecto', en que el chantajeado para que asesine tiene una estrecha relación con la mujer que debe asesinar. Se recrea la antigua en la nueva película con detalles inexistentes en la primigenia o con frases o escenas de 'gaz' de las que carecía la primera atendiendo al público o al tiempo actual con el fin de actualizar los diálogos o las situaciones. A todo ello se suma la intervención de un nuevo director cuyo ritmo y selección de planos y tomas, así como de otras actividades propias de él llevarán a una presentación diferente de la película que ha sido objeto de remake"73.

Consideramos que la diferencia con la secuela se encontraría en que esta precisa de un grado de originalidad mayor, porque únicamente se tomarán ciertos elementos de una obra anterior (la originaria), siendo el resto de la creación "original". Sin embargo, en el remake el grado de originalidad, así como de libertad creativa, será claramente menor, al consistir en "rehacer" la obra anterior.

${ }^{71}$ Este autor utiliza la expresión 'autofagia audiovisual' de forma metafórica. El término 'autofagia' se deriva de las raíces griegas auto - uno mismo; phagos - comer.

72 ÉCIJA BERNAL, H. Libro Blanco del Audiovisual: Cómo producir, distribuir y financiar una obra audiovisual, Ed. Exportfilm, Madrid, 2000, pág. 45.

73 PÉREZ DE CASTRO, N. "Remakes de películas y autores de la versión original" en Creaciones audiovisuales y propiedad intelectual, (coord. Rogel Vide, C.) Ed. REUS, Madrid, 2001, pág. 116. 


\section{2. El spin off}

Se trataría, como en el caso del remake, de un término anglosajón que tiene varias acepciones, siendo quizás más conocida la que hace referencia al mundo empresarial. No obstante, a los efectos de este artículo, la acepción a la que debemos prestar atención es la relativa al campo audiovisual.

A pesar de que el uso común de este término se lleva a cabo en inglés, para una mejor comprensión en castellano, se podría traducir literalmente como "escindir".

El spin off, es definido por CASCAJOSA como"un procedimiento de transformación temática a través del cual un personaje tiene mayor importancia en el sistema de valores del hipertexto ${ }^{74}$ de lo que tenía en el hipotexto"75.

Otra definición que podríamos mencionar es la de MARISCAL GARRIDO-FALLA, que considera que "es una obra audiovisual derivada creada a partir de un personaje (normalmente secundario) de una obra preexistente. La peculiaridad de esta transformación es que este personaje es situado en la nueva obra completamente descontextualizado, es decir, en un entorno, tiempo y espacio completamente diferentes a los de la obra originaria"76.

En efecto, no son pocos los casos que se podrían mencionar de series o películas que han surgido como spin off de otras. A modo de ejemplo, Better call Saul de la serie Breaking Bad, o Creed que es un spin off de las películas de Rocky, donde la historia gira entorno al hijo ilegítimo de Apollo Creed. No obstante, tampoco es necesario irse tan lejos para ver que este fenómeno también ocurre en España, como es el caso de Aída que es un personaje de la serie Siete vidas.

\section{CONCLUSIONES}

Que la secuela se enfrenta a una realidad compleja resulta una obviedad. En primer lugar, consideramos que existe la necesidad de singularizar esta figura respecto del resto de obras derivadas que se encontrarían junto a ella en lo que hemos denominado como cajón

74 Dentro de la teoría de la intertextualidad, el término "hipotexto" se utiliza para referirse a las obras originarias (las fuentes), mientras que el término "hipertexto" se usa para las obras basadas en las primeras.

75 CASCAJOSA VIRINO, C., El espejo deformado. Versiones, secuelas y adaptaciones en Hollywood. Universidad de Sevilla, 2006, pág. 125.

76 MARISCAL GARRIDO-FALLA, P., op. cit., nota 23. 
de sastre del art. 11 TRLPI. Ello es así porque el grado de originalidad que será exigido oscilará notablemente de unas a otras.

Por otro lado, se trata de una figura que debe mantener un delicado equilibrio, para poder reclamar su estatus singular. Esto es así porque si la secuela, como obra derivada, se apropiase de demasiados elementos de la obra originaria, correría el riesgo de ser un plagio ${ }^{77}$; si por el contrario su originalidad fuese elevada, se consideraría una obra original.

No obstante, no existiría problemática alguna cuando a la hora de crear una obra, un autor se inspire en otra. Sin embargo, y en línea con lo que hemos dicho, la inspiración requiere que no haya un apropiación indebida de los rasgos originales que servirían para justificar la protección bajo el derecho de autor. Así, habrá plagio en todos los casos en que la creación posterior no se pueda independizar suficientemente de la creación original, rompiendo así su vínculo con ésta.

Sin embargo, la discusión entorno a la cuestión de la originalidad como elemento relevante a la hora de proporcionar protección a la secuela en particular, así como a otras creaciones en general bajo el paraguas de la propiedad intelectual, no se encuentra zanjada. Como hemos apuntado con anterioridad, sigue centrando el debate jurídico hasta nuestros días, como lo demuestran las recientes conclusiones del Abogado General del TJUE. Así pues, vemos como los diferentes criterios que han sido desarrollados por la doctrina y aplicados por los tribunales en distintos países constituyen, sin duda, una herramienta útil para poder hacer una distinción de originalidad entre obra originaria y obra derivada (secuela), si bien, tales criterios, formalistas, podrían revelarse obsoletos. Lo cierto es que no podemos obviar la corriente

77 Conforme ha señalado la jurisprudencia, "por plagio hay que entender, en su acepción más simplista, todo aquello que supone copiar obras ajenas en lo sustancial. Se presenta más bien como una actividad material mecanizada y muy poco intelectual y menos creativa, carente de toda originalidad y de concurrencia de genio o talento humano, aunque aporte cierta manifestación de ingenio. Las situaciones que representan plagio hay que entenderlas como las de identidad, así como las encubiertas, pero que descubren, al despojarse de los ardides y ropajes que las disfrazan, su total similitud con la obra original, produciendo un estado de apropiación y aprovechamiento de la labor creativa y esfuerzo ideario o intelectivo. No procede [produce] confusión con todo aquello que es común e integra el acervo cultural generalizado o con los datos que las ciencias aportan para el acceso y el conocimiento por todos, con lo que se excluye lo que supone efectiva realidad inventiva, sino más bien relativa, que surge de la inspiración de los hombres y difícilmente, salvo casos excepcionales, alcanza neta, pura y total invención, desnuda de toda aportación posterior. Por todo lo cual, el concepto de plagio ha de referirse a las coincidencias estructurales básicas y fundamentales y no a las accesorias, añadidas, superpuestas o modificaciones no trascendentales». STS de 28 de enero de 1.995 (ROJ: 10370/1995). 
de armonización que en materia de originalidad persigue la jurisprudencia del TJUE, debiendo, por ello, avanzar hacia la adopción de una originalidad desde la tesis subjetiva. Efectivamente, es nuestro parecer que un planteamiento estrictamente formal podría conducir a situaciones contrarias a la pretendida por el legislador, que es la protección de las obras del espíritu al mismo tiempo que la figura del autor. 
